\title{
Association of Primary and Specialty Care Integration on Physician Communication and Cancer Screening in Safety-Net Clinics
}

\author{
Ashley M. Kranz, $\mathrm{PhD}^{1}$; Jamie Ryan, $\mathrm{MPH}^{2}$; Ammarah Mahmud, $\mathrm{MPH}^{1}$; Claude Messan Setodji, $\mathrm{PhD}^{3}$; \\ Cheryl L. Damberg, $\mathrm{PhD}^{4}$; Justin W. Timbie, $\mathrm{PhD}^{1}$
}

\begin{abstract}
Accessible Version: www.cdc.gov/pcd/issues/2020/20_0025.htm
Suggested citation for this article: Kranz AM, Ryan J, Mahmud A, Setodji CM, Damberg CL, Timbie JW. Association of Primary and Specialty Care Integration on Physician Communication and Cancer Screening in Safety-Net Clinics. Prev Chronic Dis 2020; 17:200025. DOI: https://doi.org/10.5888/pcd17.200025.
\end{abstract}

\section{PEER REVIEWED}

\section{Summary}

What is already known on this topic?

Community health centers (CHCs) provide primary care to disadvantaged populations and have lower-than-average cancer screening rates. Stronger integration of $\mathrm{CHCs}$ and specialists is recommended to increase cancer screening, but the impact of integration efforts in the real world is unknown.

\section{What is added by this report?}

$\mathrm{CHCs}$ that are more strongly integrated with specialists have higher rates of cervical and colorectal cancer screening and better communication with specialists compared with the least integrated CHCs.

What are the implications for public health practice?

Integration between $\mathrm{CHCs}$ and specialists may enhance communication across health care providers and improve cancer screening rates. Efforts are needed to promote integration and identify the mechanisms that lead to long-term, effective partnerships.

\section{Abstract}

\section{Introduction}

Primary care providers who lack reliable referral relationships with specialists may be less likely than those who do have such relationships to conduct cancer screenings. Community health centers (CHCs), which provide primary care to disadvantaged populations, have historically reported difficulty accessing specialty care for their patients. This study aimed to describe strategies CHCs use to integrate care with specialists and examine whether more strongly integrated CHCs have higher rates of screening for colorectal and cervical cancers and report better communication with specialists.

\section{Methods}

Using a 2017 survey of CHCs in 12 states and the District of Columbia and administrative data, we estimated the association between a composite measure of $\mathrm{CHC} /$ specialist integration and 1) colorectal and cervical cancer screening rates, and 2) 4 measures of $\mathrm{CHC} /$ specialist communication using multivariate regression models.

\section{Results}

Integration strategies commonly reported by CHCs included having specialists deliver care on-site $(80 \%)$ and establishing referral agreements with specialists $(70 \%)$. CHCs that were most integrated with specialists had 5.6 and 6.8 percentage-point higher colorectal and cervical cancer screening rates, respectively, than the least integrated CHCs $(P<.05)$. They also had significantly higher rates of knowing that specialist visits happened $(67 \%$ vs $42 \%$ ), knowing visit outcomes ( $65 \%$ vs $42 \%$ ), receiving information after visits ( $47 \%$ vs $21 \%$ ), and timely receipt of information (44\% vs $27 \%)$.

\section{Conclusion}

CHCs use various strategies to integrate primary and specialty care. Efforts to promote $\mathrm{CHC} /$ specialist integration may help increase rates of cancer screening.

\section{Introduction}

Community health centers (CHCs), a type of federally qualified health center, provide primary care to racially/ethnically diverse and economically disadvantaged populations, regardless of ability to pay (1). Given the widespread inequities in cancer screening for racial/ethnic minority populations and the uninsured $(2,3)$, CHCs 
are well-positioned to close gaps in cancer screening because of their focus on serving vulnerable populations and commitment to quality measurement and quality improvement activities.

Systematic reviews have documented barriers to and strategies for increasing cancer screening $(4,5)$, including those specific to CHCs $(6,7)$. CHC strategies to increase cancer screening include using patient navigators to help patients understand the screening process and complete follow-up appointments $(4,6)$, reminding providers about the importance of screenings (5), giving providers feedback, and tracking the return of tests $(5,7)$. Despite these efforts, colorectal and cervical cancer screening rates in $\mathrm{CHCs}$ remain low (1).

Although many cancer screening tests can be conducted in $\mathrm{CHCs}$, specialty care is needed for some tests (eg, colonoscopies) and for follow-up care after patients receive abnormal or positive test results (eg, referrals to gynecologic oncologists for diagnoses of invasive cervical cancer). CHCs have reported that a barrier to cancer screening is their inability to refer patients needing follow-up care (7); thus, stronger integration of specialists and $\mathrm{CHCs}$ is recommended to increase screening rates (8). In addition to encouraging screening at $\mathrm{CHCs}$, integration can facilitate communication between CHCs and specialists, which is needed for tracking referrals to specialists and the results of those referrals and coordinating care across multiple providers and settings (8). For example, some $\mathrm{CHCs}$ have reported challenges in tracking follow-up care for patients with positive cancer screening results who they referred to specialists (9). Although most CHCs report the ability to exchange information with hospitals and specialists (1), this information may be limited or delayed (10), which may hinder communication between $\mathrm{CHCs}$ and specialists and appropriate followup care.

Despite the potential benefits of $\mathrm{CHC} /$ specialist integration, to our knowledge, no studies have examined its effect on cancer screening rates and $\mathrm{CHC} /$ specialist communication. Our study addresses gaps in the literature by combining survey and administrative data to describe the strategies CHCs are using to integrate care with specialists and to examine the extent to which more strongly integrated $\mathrm{CHCs}$ have higher rates of screening for colorectal and cervical cancers and report better communication with specialists.

\section{Methods}

\section{Data sources}

This cross-sectional study used a survey developed by the authors and completed in summer 2017 by medical directors at CHCs funded by the Health Resources and Services Administration (HRSA) in 12 states (California, Colorado, Illinois, Louisiana, Maine, Min- nesota, New Jersey, Oregon, Utah, Vermont, Washington, and Wisconsin) and the District of Columbia. The survey was fielded as part of a larger effort to describe the landscape of care integration activities involving CHCs, specialty practices, hospitals, and social service organizations (10-12). We purposely sampled states to include those with active Medicaid accountable care organizations (ACOs) at the time of the survey ( 7 states), because these programs may promote greater accountability for providing more coordinated care across settings. We added 5 states (California, Illinois, Louisiana, Washington, and Wisconsin) and the District of Columbia to improve geographic diversity and to include states that expanded Medicaid under the Affordable Care Act and states that did not. Medicaid expansion may reduce the number of uninsured in a state and ease some barriers to referrals and care coordination. We supplemented these survey data with data from HRSA's Uniform Data System (UDS) database (13), which provided contact information for medical directors and information on $\mathrm{CHC}$ characteristics and quality of care measures.

\section{Conceptual model}

Building on previous research examining strategies to increase cervical and colorectal cancer screening in $\mathrm{CHCs}(7,8,14)$, we hypothesized that stronger $\mathrm{CHC} /$ specialist integration would increase cancer screening through 2 related mechanisms. First, improving links between $\mathrm{CHCs}$ and specialists is a recommended strategy for increasing access to more invasive screening modalities not traditionally offered at CHCs (eg, colonoscopies) (8). Second, because the inability of health care providers to refer patients needing follow-up care is a barrier to cancer screening (7), we hypothesized that more strongly integrated CHCs would conduct more screenings because they have more reliable (or any) referral options available to patients who need additional testing and follow-up care after receiving abnormal screening results. We further hypothesized that stronger $\mathrm{CHC} /$ specialist integration would improve communication between $\mathrm{CHCs}$ and specialists. Relationships with specialists have been identified as a key component of successful screening programs (8), whereas problems coordinating with external laboratories and specialists have been identified as a barrier to cancer screening (14). Thus, stronger $\mathrm{CHC} /$ specialist integration may lead to the establishment of communication agreements and encourage more timely information sharing and better follow-up care. Our study tested the associations between $\mathrm{CHC} /$ specialist integration and 1) screening rates for colorectal and cervical cancers and 2) communication between $\mathrm{CHCs}$ and specialty care providers.

\section{Survey}

Our main data source was a 30-minute web-based survey completed by $\mathrm{CHC}$ medical directors in 12 states and the District of

\footnotetext{
The opinions expressed by authors contributing to this journal do not necessarily reflect the opinions of the U.S. Department of Health and Human Services, the Public Health Service, the Centers for Disease Control and Prevention, or the authors' affiliated institutions.
} 
Columbia. The survey gathered information about how $\mathrm{CHCs}$ collaborate with hospitals (10), social service organizations (11), and specialists (12), with specialists being the focus of this study. Survey items were informed by a review of the literature and by interviews with subject matter experts and representatives of $\mathrm{CHCs}$ and state primary care associations, which provide training and technical assistance to safety-net providers. We used items from existing surveys when possible (15-17). We obtained comments on the draft survey from primary care associations. We conducted cognitive interviews with $3 \mathrm{CHC}$ medical directors outside our sample to ensure that survey items elicited the intended information. We offered respondents an incentive of a $\$ 50$ gift card for survey completion, which was later increased to $\$ 100$ to improve the response rate after 4 weeks in the field. Of $407 \mathrm{CHCs}$ invited to complete the survey, 215 responded to the items used in this analysis (response rate, $52.8 \%$ ).

\section{Variables}

The survey consisted of 12 items (Appendix). We use 4 items related to $\mathrm{CHC} /$ specialist communication as dependent variables to indicate whether the CHC "often" or "always" 1) knew that a specialist visit happened, 2) knew the visit's outcome, 3) received clear recommendations on follow-up and care management after the specialist visit, and 4) received results or recommendations from the specialist in a timely manner.

We constructed a composite measure of $\mathrm{CHC} /$ specialist integration to summarize the breadth of strategies used by CHCs to achieve greater integration with specialty care providers. The composite included strategies focused on improving referrals (establishing referral agreements, participating in e-consults, making specialist appointments for patients, and reminding patients about those appointments), aligning goals with specialists (through quality improvement projects or health promotion initiatives), information exchange (ability to send data electronically to specialist, ability to read specialists' electronic health records [EHRs] in real time), and improving access (by providing specialty care on-site, expanding telemedicine, and developing affiliations with hospitals). An additional variable included in the composite measure provided a count of the types of provisions included in referral agreements between $\mathrm{CHCs}$ and specialists. We developed the composite of CHCs' overall integration with specialists using a 1factor confirmatory factor analysis. We assessed goodness-of-fit by the comparative fit index $(0.78)$ and the root mean square error of approximation (0.13). Higher values of the integration composite indicate stronger $\mathrm{CHC} /$ specialist integration. We categorized $\mathrm{CHCs}$ as having low, medium, and high levels of integration by dividing CHCs into tertiles based on the composite measure score. Additional survey items provided information on the characteristics of the survey respondents and characteristics of the $\mathrm{CHCs}$, such as whether the CHC reported "often" or "always" having a chaotic practice environment and having levels of physician turnover that affected the CHC's ability to care for patients (18). We used the 2011-2015 American Community Survey's 5-year pooled files to derive a 6-item composite measure of neighborhood socioeconomic status for the primary care service area in which a plurality of each health center's patient population lives (19).

HRSA's UDS provides information on rates of screening for colorectal and cervical cancer in $\mathrm{CHCs}$, which includes screenings conducted both at the $\mathrm{CHC}$ and off-site (eg, through referral) (13). We also used 2 performance measures from the UDS for falsification tests; we hypothesized that measures of screening for healthy weight among adults and screening for tobacco use (and provision of cessation intervention for active smokers) among adults would be unaffected by $\mathrm{CHC} /$ specialist integration. We also obtained data on the following characteristics of patients and CHCs from the UDS: total number of patients; number of service sites; percentage of patients who were uninsured, enrolled in Medicaid, or belonged to a racial/ethnic minority group; number of primary care providers per 10,000 patients; number of enablingservice providers per 10,000 patients; and rural or urban location. All UDS variables are reported at the level of the $\mathrm{CHC}$ grantee (and the survey was administered at the grantee level), which often includes multiple service sites (13).

\section{Analysis}

To assess the representativeness of our study sample, we used measures from the 2017 UDS to compare characteristics of CHCs that responded to the survey and those that did not in our surveyed states. Then, we described strategies used by CHCs to integrate care with specialists. Next, we fit linear regression models to examine the association between the composite measure of $\mathrm{CHC} /$ specialist integration and rates of screening for colorectal and cervical cancers and to conduct falsification tests using the other UDS measures that were not expected to be associated with $\mathrm{CHC} /$ specialist integration. We also use logistic regression models to examine the associations between overall $\mathrm{CHC} /$ specialist integration and the 4 measures of $\mathrm{CHC}$ /specialist communication. We tabulated the results from the logistic regression models as predicted probabilities for each level of the integration index, leaving all other variables at their actual values, and compared these probabilities across integration tertiles using Wald $\chi^{2}$ tests. All regression models adjusted for the aforementioned characteristics and included robust standard errors. We performed all analyses using Stata version 16 (StataCorp LLC) and used $P<.05$ to identify significance. The study was approved by the RAND institutional review board.

The opinions expressed by authors contributing to this journal do not necessarily reflect the opinions of the U.S. Department of Health and Human Services, the Public Health Service, the Centers for Disease Control and Prevention, or the authors' affiliated institutions. 


\section{Results}

The 215 responding CHCs serve an average of 24,398 patients annually (median, 13,700), primarily in urban communities (Table 1). Across CHCs, one-fifth (20.4\%) of patients were uninsured, more than half (53.2\%) were enrolled in Medicaid, and 60.2\% were racial/ethnic minority patients. $\mathrm{CHCs}$ report an average of 9.7 primary care physician FTEs per 10,000 patients, and 40.6\% of respondents reported that physician turnover affects the quality of care in their organization. Approximately 1 in 6 respondents $(17.9 \%)$ report a chaotic practice environment in their CHC. Our sample of CHCs served patients in vulnerable communities, where the annual household income was below the federal poverty level in $20.0 \%$ of household incomes, on average. On average, CHCs reported screening $43.1 \%$ of eligible patients for colorectal cancer and $54.5 \%$ of eligible patients for cervical cancer. On average, CHCs in the highest tertile served more patients, served a higher percentage of patients enrolled in Medicaid, and reported a less chaotic practice environment. Most survey respondents $(64.8 \%)$ were medical directors and $51.6 \%$ had worked at their $\mathrm{CHC}$ for more than 5 years. CHCs responding to the survey were similar to nonrespondents on nearly all characteristics, except that responding CHCs served a slightly lower percentage of patients identified as racial/ethnic minority $(60.2 \%$ vs $66.6 \%)$.

CHCs reported using various strategies to support the integration of primary and specialty care (Table 2). Most commonly, 80.5\% of CHCs reported that on-site specialists provided any care during the previous 6 months. CHCs also frequently reported participating in quality improvement projects with specialty practices or participating in joint health promotion activities $(71.2 \%)$ and having established agreements with specialists about the types of referrals specialists will accept or information the health center will provide when making a referral $(70.2 \%)$. Less common strategies for $\mathrm{CHC} /$ specialist integration reported by $\mathrm{CHCs}$ include using econsults (43.7\%) and telemedicine $(29.3 \%)$ and the ability to read the EHRs of specialists in real-time (24.7\%). CHCs in the highest tertile of $\mathrm{CHC} /$ specialist integration were consistently more likely to report engaging in strategies supporting $\mathrm{CHC} /$ specialist integration than CHCs in the lowest tertile of integration (Table 2). For example, $\mathrm{CHCs}$ in the highest tertile were more likely to report making appointments on behalf of patients $(67.1 \%$ vs $47.9 \%)$ and report the ability to read specialists' EHRs in real time $(38.4 \% \mathrm{vs}$ $15.5 \%)$.

Higher levels of $\mathrm{CHC} /$ specialty integration were associated with higher rates of cancer screening in analyses that adjusted for possible confounders (Table 3 ). For example, the highest tertile of $\mathrm{CHC} /$ specialty integration was associated with a 5.6 percentagepoint higher colorectal cancer screening rate $(P=.047)$ and a 6.8 percentage-point higher cervical cancer screening rate $(P=.01)$ compared with the lowest tertile. Similarly, the middle tertile of $\mathrm{CHC} /$ specialty integration was associated with a 5.4 percentagepoint higher colorectal cancer screening rate $(P=.04)$ and a 7.0 percentage-point higher cervical cancer screening rate $(P=.008)$ compared with the lowest tertile. We found no significant differences between CHCs in the middle tertile and CHCs in the highest tertile of integration. Results of our falsification tests found no significant association between $\mathrm{CHC}$ /specialty integration and healthy weight screening for adults and tobacco screening and cessation intervention for adults, outcomes we hypothesized would not be affected by $\mathrm{CHC} /$ specialty integration.

We also found an association between $\mathrm{CHC} /$ specialist integration and the 4 measures of $\mathrm{CHC} /$ specialist communication (Figure). $\mathrm{CHCs}$ in the highest tertile of integration were estimated to have better rates of $\mathrm{CHC} /$ specialist communication, adjusting for a range of $\mathrm{CHC}$ characteristics, when compared with $\mathrm{CHCs}$ in the lowest tertile of integration. For example, $64.6 \%$ of $\mathrm{CHCs}$ in the highest tertile of integration reported knowing the outcome of a specialist visit compared with $41.7 \%$ of CHCs in the lowest tertile of integration $(P=.007)$. The largest differences between $\mathrm{CHCs}$ in the highest and lowest tertiles were in the extent to which $\mathrm{CHCs}$ reported receiving clear recommendations on follow-up and care management after a specialist visit (26.2 percentage-point difference; $P<.001$ ) and the extent to which CHCs knew that a specialty visits happened (24.7 percentage-point difference, $P=.004$ ). The only significant difference observed between the middle and lowest tertiles was for the extent to which $\mathrm{CHCs}$ reported receiving clear recommendations on follow-up and care management after a specialist visit (15.6 percentage-point difference, $P=.04$ ).

The opinions expressed by authors contributing to this journal do not necessarily reflect the opinions of the U.S. Department of Health and Human Services, the Public Health Service, the Centers for Disease Control and Prevention, or the authors' affiliated institutions. 


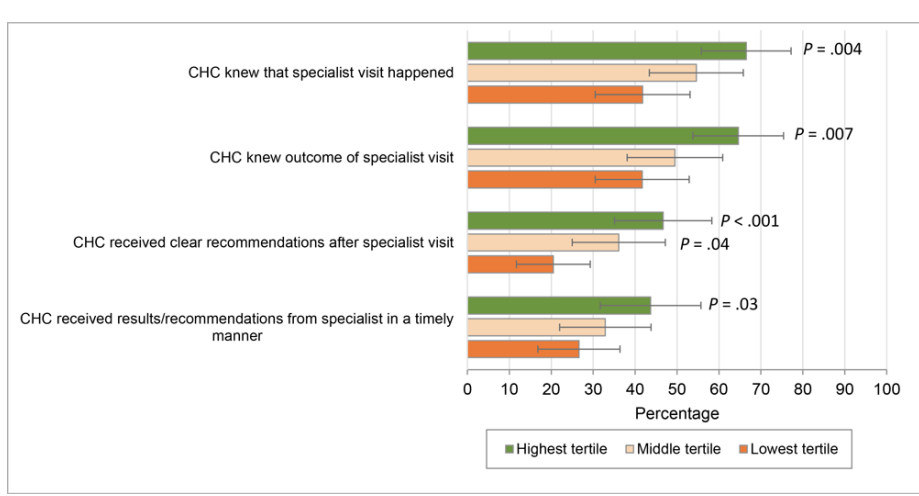

Figure. Predicted probabilities of measures of $\mathrm{CHC} /$ specialist communication by tertile of $\mathrm{CHC} / \mathrm{specialist}$ integration. We used 4 items related to $\mathrm{CHC} / \mathrm{specialist}$ communication as dependent variables to indicate whether the CHC "often" or "always" 1) knew that a specialist visit happened, 2) knew the outcome of a specialty visit, 3 ) received clear recommendations on followup and care management after the specialist visit, and 4) received results or recommendations from the specialist in a timely manner. Each item was dichotomized according to the empirical distribution of responses (reference group combined responses of "never," "rarely," and "sometimes"). P values are for comparisons with the lowest tertile. Abbreviation: $\mathrm{CHC}$, community health clinic.

\section{Discussion}

In this multistate, cross-sectional study of CHCs, we found that CHCs most strongly integrated with specialists had higher rates of screening for colorectal and cervical cancers and were more likely to report successful $\mathrm{CHC} /$ specialist communication than the least integrated CHCs. The integration of specialists and $\mathrm{CHCs}$ is recommended as a strategy for increasing cancer screening in $\mathrm{CHCs}$ (8), and this study provides additional evidence in support of this approach. Stronger integration likely reduces barriers related to obtaining referrals for patients needing invasive testing or followup care, which has previously been reported by $\mathrm{CHCs}$ as a barrier to cancer screening (7). Additionally, more strongly integrated CHCs may have implemented effective strategies to strengthen referral processes, such as ensuring that specialists have all needed tests and information at the time of the patient's visit, limiting referrals to only those that are necessary, and reducing no-shows through patient reminders (20). Conversely, at CHCs that are poorly integrated with specialists, patients may struggle to navigate multiple providers, miss appointments, and fail to complete screenings once they are referred to specialists, a challenge previously reported by CHCs in Washington state (9).

Along with higher rates of cancer screening, we found that stronger $\mathrm{CHC} /$ specialist integration was associated with better communication between $\mathrm{CHCs}$ and specialists. Information exchange between $\mathrm{CHCs}$ and specialists is essential for successful cancer screening programs. For example, poorly integrated CHCs might not receive the results of cancer screenings conducted outside their clinic, and thus have no record of completed screenings, which could lead to undercounting of screenings or duplicative screenings. O’Malley and Reschovsky reported a disconnect between information shared between primary care providers and specialists: more specialists reported sending results to primary care providers than primary care providers reported receiving such results, and vice versa (21). Real-time access to specialists' electronic health records can address this challenge by allowing $\mathrm{CHC}$ staff to obtain test results, notes, and follow-up care recommendations when needed rather than relying on specialists to send this information; real-time access to specialist records was reported by $38 \%$ of the $\mathrm{CHCs}$ most integrated with specialists in our sample compared with $16 \%$ of the CHCs least integrated with specialists. Importantly, these efforts require all levels of staff. Director-level staff members can implement system-level strategies to facilitate $\mathrm{CHC}$ and specialist relationships, while these relationships are maintained by the coordination activities of staff members such as patient navigators.

Additionally, we found that nearly three-quarters of CHCs participated in quality improvement projects or health promotion initiatives with specialists in their communities. Engaging in such activities can help solidify local communities of practice. Taplin and colleagues found that screening rates for colorectal and cervical cancer increased among $4 \mathrm{CHCs}$ that had established communities of practice with specialists and other community stakeholders and engaged in a regional cancer collaborative demonstration project (22). Additionally, building formal partnerships with local community hospitals and teaching hospitals may help promote access to specialty care for CHC patients (23). Furthermore, collaborations between $\mathrm{CHCs}$ and specialists are now supported by the HRSA's Health Center Program statute, which outlines the requirements $\mathrm{CHCs}$ must meet to receive federal funding. In $\mathrm{Au}-$ gust 2018, HRSA updated the Health Center Program statute to explicitly require CHCs "to make every reasonable effort" to collaborate with nearby specialists (24). HRSA should monitor these integration efforts and support implementation research that can identify the most effective integration strategies, facilitate the development of quality measures that can assess uptake of these strategies, and, overall, accelerate the delivery of effective approaches.

Despite the efforts by $\mathrm{CHCs}$, barriers to stronger $\mathrm{CHC} /$ specialist integration remain, particularly $\mathrm{CHCs}^{\prime}$ patient mix, which is overwhelmingly Medicaid (53.2\%) or uninsured (20.4\%). CHCs have historically reported difficulty in obtaining specialist appointments and procedures for their uninsured and Medicaid patients $(12,25,26)$. Establishing referral agreements with specialists is a recommended strategy for improving referral success, and a

The opinions expressed by authors contributing to this journal do not necessarily reflect the opinions of the U.S. Department of Health and Human Services, the Public Health Service, the Centers for Disease Control and Prevention, or the authors' affiliated institutions. 
strategy reported by more than $70 \%$ of CHCs in this study, but establishing these agreements can be challenging if specialists in the community are unwilling to accept referrals for uninsured patients (27). Furthermore, particularly for rural CHCs, there may be few specialists in close proximity with whom to coordinate (28). Additionally, smaller CHCs may have fewer resources and staff to devote to pursuing and maintaining these relationships. Thus, various strategies are likely needed to increase cancer screening for CHC patients.

This study has several limitations. In this cross-sectional study, we cannot determine whether stronger integration promotes cancer screening, or whether better-performing CHCs are more likely to pursue integrated care strategies. Although we developed a set of integration strategies used by $\mathrm{CHCs}$ based on a review of the literature and input from experts, other strategies may exist that we did not capture. Additionally, as with all survey research, survey responses may be affected by social desirability bias if respondents answered the items in a way that they thought would be viewed favorably rather than reflecting actual care in their CHC. Furthermore, although we conducted cognitive testing in an attempt to ensure survey items elicited the intended information, we cannot be certain that all items were interpreted as intended. Although the model fit statistics estimated for our integration measure slightly exceeded standard recommendations (ie, comparative fit index $>0.90$ and root mean square error of approximation $<0.10$ ), suggesting that the included items might support more than 1 underlying factor, we considered the interpretability of a single-factor model to be more important than meeting goodness-of-fit criteria $(29,30)$. Finally, although we studied a geographically diverse sample of states and respondents varied in extent of integration and rates of screening, our convenience sample of states is not nationally representative, which may limit the generalizability of these findings nationally. As a comparison, average rates of screening for colorectal cancer (CHCs studied, $43.1 \%$ vs $42.0 \%$ nationally) and cervical cancer (54.5\% CHCs studied vs $55.7 \%$ nationally) were similar for $\mathrm{CHCs}$ studied and $\mathrm{CHCs}$ nationally.

We found that $\mathrm{CHCs}$ that were strongly integrated with specialists reported higher cancer screening rates and better communication with specialists than the least integrated CHCs. This finding is important given the low rates of colorectal and cervical cancer screening in CHCs and, because CHCs serve a racially/ethnically diverse and economically disadvantaged patient population, increasing rates of cancer screening in $\mathrm{CHCs}$ can help to reduce overall inequities in cancer screening. CHCs are using various strategies to integrate care with specialists and to meet the needs of their patients, and more strategies are likely to be developed and adopted in response to HRSA's policy change that further emphasizes CHCs' need to integrate care with specialists. Further re- search is needed to better understand the challenges faced by $\mathrm{CHCs}$ that are weakly integrated with specialists and to determine how to help them realize the potential benefits of greater integration for the quality of care for their patients.

\section{Acknowledgments}

This work was supported through the RAND Center of Excellence on Health System Performance, which is funded through a cooperative agreement (1U19HS024067-01) between the RAND Corporation and the Agency for Healthcare Research and Quality (AHRQ). The content and opinions expressed in this publication are solely the responsibility of the authors and do not reflect the official position of AHRQ or the US Department of Health and Human Services.

Information about survey respondents and nonrespondents and the results of falsification tests are available from the corresponding author upon request. No copyrighted materials were used in the conduct of this research.

\section{Author Information}

Corresponding Author: Ashley M. Kranz, PhD, RAND, 1200 S Hayes St, Arlington, VA 22202. Telephone: 703-413-1100 x5616. Email: Akranz@rand.org.

Author Affiliations: ${ }^{1}$ RAND, Arlington, Virginia. ${ }^{2}$ Pardee RAND Graduate School, Santa Monica, California. ${ }^{3}$ RAND, Pittsburgh, Pennsylvania. ${ }^{4}$ RAND, Santa Monica, California.

\section{References}

1. Health Resources and Services Administration. National health center data. 2019. https://bphc.hrsa.gov/uds/datacenter.aspx. Accessed November 20, 2019.

2. White A, Thompson TD, White MC, Sabatino SA, de Moor J, Doria-Rose PV, et al. Cancer screening test use - United States, 2015. MMWR Morb Mortal Wkly Rep 2017; 66(8):201-6.

3. Borsky A, Mitchell E, Machlin S, Bierman A, Zhan C, Miller $\mathrm{T}$, et al.Use of clinical preventive services in the United States: estimates from the Medical Expenditure Panel Survey (MEPS), 2015. Rockville (MD): Agency for Healthcare Research and Quality; 2019. https://meps.ahrq.gov/data_files/publications/ rf41/rf41.shtml. Accessed July 30, 2020.

The opinions expressed by authors contributing to this journal do not necessarily reflect the opinions of the U.S. Department of Health and Human Services, the Public Health Service, the Centers for Disease Control and Prevention, or the authors' affiliated institutions. 
4. Sabatino SA, Lawrence B, Elder R, Mercer SL, Wilson KM, DeVinney B, et al.; Community Preventive Services Task Force. Effectiveness of interventions to increase screening for breast, cervical, and colorectal cancers: nine updated systematic reviews for the Guide to Community Preventive Services. Am J Prev Med 2012;43(1):97-118.

5. Holden DJ, Jonas DE, Porterfield DS, Reuland D, Harris R. Systematic review: enhancing the use and quality of colorectal cancer screening. Ann Intern Med 2010;152(10):668-76.

6. Domingo JB, Braun KL. Characteristics of effective colorectal cancer screening navigation programs in federally qualified health centers: a systematic review. J Health Care Poor Underserved 2017;28(1):108-26.

7. Daly JM, Levy BT, Moss CA, Bay CP. System strategies for colorectal cancer screening at federally qualified health centers. Am J Public Health 2015;105(1):212-9.

8. Sarfaty M, Doroshenk M, Hotz J, Brooks D, Hayashi S, Davis $\mathrm{TC}$, et al. Strategies for expanding colorectal cancer screening at community health centers. CA Cancer J Clin 2013; 63(4):221-31.

9. Martinez-Gutierrez J, Jhingan E, Angulo A, Jimenez R, Thompson B, Coronado GD. Cancer screening at a federally qualified health center: a qualitative study on organizational challenges in the era of the patient-centered medical home. J Immigr Minor Health 2013;15(5):993-1000.

10. Timbie JW, Kranz AM, Mahmud A, Setodji CM, Damberg CL. Federally qualified health center strategies for integrating care with hospitals and their association with measures of communication. Jt Comm J Qual Patient Saf 2019; 45(9):620-8.

11. Kranz AM, Mahmud A, Agniel D, Damberg C, Timbie JW. Provision of social services and health care quality in US community health centers, 2017. Am J Public Health 2020; 110(4):567-73.

12. Timbie JW, Kranz AM, Mahmud A, Damberg CL. Specialty care access for Medicaid enrollees in expansion states. Am J Manag Care 2019;25(3):e83-7.

13. Health Resources and Services Administration, Bureau of Primary Health Care. Uniform Data System: reporting instructions for 2017 health center data. 2017. https:// bphc.hrsa.gov/sites/default/files/bphc/datareporting/reporting/ 2017udsreportingmanual.pdf. Accessed October 10, 2019.

14. Moshkovich O, Lebrun-Harris L, Makaroff L, Chidambaran P, Chung M, Sripipatana A, et al. Challenges and opportunities to improve cervical cancer screening rates in US health centers through patient-centered medical home transformation. Adv Prev Med 2015;2015:182073.
15. Singer SJ, Burgers J, Friedberg M, Rosenthal MB, Leape L, Schneider E. Defining and measuring integrated patient care: promoting the next frontier in health care delivery. Med Care Res Rev 2011;68(1):112-27.

16. Derrett S, Gunter KE, Samaranayaka A, Singer SJ, Nocon RS, Quinn MT, et al. Development and testing of the Provider and Staff Perceptions of Integrated Care (PSPIC) survey. Med Care Res Rev 2019;76(6):807-29.

17. The Commonwealth Fund. 2013 Survey of federally qualified health centers. 2014. https://www.commonwealthfund.org/ sites/default/files/documents/__media_files_surveys_2014_ 2013_fqhc_hard_copy_questionnaire.pdf. Accessed October $12,2019$.

18. Linzer M, Manwell LB, Williams ES, Bobula JA, Brown RL, Varkey AB, et al. Working conditions in primary care: physician reactions and care quality. Ann Intern Med 2009; 151(1):28-36, W6-9.

19. Bird CE, Seeman T, Escarce JJ, Basurto-Dávila R, Finch BK, Dubowitz T, et al. Neighbourhood socioeconomic status and biological 'wear and tear' in a nationally representative sample of US adults. J Epidemiol Community Health 2010; 64(10):860-5.

20. The Commonwealth Fund. Safety Net Medical Home Initiative. Care coordination: reducing fragmentation in primary care. 2013. http://www.safetynetmedicalhome.org/ sites/default/files/Implementation-Guide-CareCoordination.pdf. Accessed October 1, 2019.

21. O’Malley AS, Reschovsky JD. Referral and consultation communication between primary care and specialist physicians: finding common ground. Arch Intern Med 2011; 171(1):56-65.

22. Taplin SH, Haggstrom D, Jacobs T, Determan A, Granger J, Montalvo W, et al. Implementing colorectal cancer screening in community health centers: addressing cancer health disparities through a regional cancer collaborative. Med Care 2008;46(9Suppl 1):S74-83.

23. Neuhausen K, Grumbach K, Bazemore A, Phillips RL. Integrating community health centers into organized delivery systems can improve access to subspecialty care. Health Aff (Millwood) 2012;31(8):1708-16.

24. Health Resources and Services Administration. Health center program compliance manual revisions. $2018 \mathrm{https}$ :// b p h c.hrsa.gov/programrequirements/pdf/ healthcentercompliancemanual-revisions.pdf. Accessed October 20, 2019.

The opinions expressed by authors contributing to this journal do not necessarily reflect the opinions of the U.S. Department of Health and Human Services, the Public Health Service, the Centers for Disease Control and Prevention, or the authors' affiliated institutions. 
25. Ryan J, Riley P, Abrams MK. How strong is the primary care safety net? Assessing the ability of federally qualified health centers to serve as patient-centered medical homes. New York (NY): The Commonwealth Fund, 2015. https:// www.commonwealthfund.org/publications/issue-briefs/2015/ sep/how-strong-primary-care-safety-net-assessing-abilityfederally. Accessed October 20, 2019.

26. Cook NL, Hicks LS, O'Malley AJ, Keegan T, Guadagnoli E, Landon BE. Access to specialty care and medical services in community health centers. Health Aff (Millwood) 2007; 26(5):1459-68.

27. Cunningham P, Felland L, Stark L. Safety-net providers in some US communities have increasingly embraced coordinated care models. Health Aff (Millwood) 2012; 31(8):1698-707.

28. Derrett S, Gunter KE, Nocon RS, Quinn MT, Coleman K, Daniel DM, et al. How 3 rural safety net clinics integrate care for patients: a qualitative case study. Med Care 2014; 52(11Suppl 4):S39-47.

29. Byrne BM. Structural equation modeling with EQS and EQS/ Windows: basic concepts, applications, and programming. Thousand Oaks (CA): Sage; 1994.

30. MacCallum RC, Browne MW, Sugawara HM. Power analysis and determination of sample size for covariance structure modeling. Psychol Methods 1996;1(2):130-49.

The opinions expressed by authors contributing to this journal do not necessarily reflect the opinions of the U.S. Department of Health and Human Services, the Public Health Service, the Centers for Disease Control and Prevention, or the authors' affiliated institutions. 


\section{Tables}

Table 1. Characteristics of Respondents $(\mathrm{N}=215)$ to a Survey of Community Health Centers (CHCs) in 12 States and the District of Columbia, 2017

\begin{tabular}{|c|c|c|c|c|}
\hline \multirow[b]{2}{*}{ Characteristic } & \multirow[b]{2}{*}{ All CHCs } & \multicolumn{3}{|c|}{ By Tertile of Integration ${ }^{b}$} \\
\hline & & Lowest & Middle & Highest \\
\hline \multicolumn{5}{|l|}{ Cancer screening rate, $\%$} \\
\hline Colorectal cancer & 43.1 & 39.8 & 44.8 & 44.6 \\
\hline Cervical cancer & 54.5 & 49.2 & 57.7 & 56.4 \\
\hline \multicolumn{5}{|l|}{ CHC characteristics } \\
\hline Mean no. (SD) of patients & $24,398(29,305)$ & $20,867(29,672)$ & $21,601(21,484)$ & $30,046(34,576)$ \\
\hline Mean no. (SD) of service sites & $8.4(8.7)$ & $7.7(9.1)$ & $7.9(6.4)$ & $9.5(10.1)$ \\
\hline Racial/ethnic minority patients, \% & 60.2 & 55.2 & 62.4 & 62.9 \\
\hline Uninsured patients, \% & 20.4 & 20.4 & 21.6 & 19.1 \\
\hline Enrolled in Medicaid, \% & 53.2 & 50.0 & 53.0 & 56.6 \\
\hline Mean primary care FTE per 10,000 patients & 9.7 & 9.6 & 10.0 & 9.5 \\
\hline Mean enabling-service FTE per 10,000 patients & 11.2 & 12.1 & 9.3 & 12.2 \\
\hline $\mathrm{CHC}$ has a chaotic environment, $\%$ & 17.9 & 23.9 & 19.1 & 10.9 \\
\hline Physician turnover affects quality of care, $\%$ & 40.6 & 42.8 & 39.2 & 39.7 \\
\hline \multicolumn{5}{|l|}{ Regional characteristics } \\
\hline Rural, \% & 38.1 & 40.8 & 39.4 & 34.2 \\
\hline State-expanded Medicaid, \% & 89.8 & 88.7 & 84.5 & 95.9 \\
\hline State has Medicaid ACO, \% & 31.6 & 33.8 & 35.2 & 26.0 \\
\hline Composite measure $^{c}$ of SES in CHC service area & -0.01 & -0.21 & 0.02 & 0.15 \\
\hline \multicolumn{5}{|c|}{ Items included in composite measure of SES of $\mathrm{CHC}$ service area } \\
\hline High school graduation rate in zip code, $\%$ & 18.4 & 16.2 & 19.2 & 19.8 \\
\hline Male unemployment rate in zip code, $\%$ & 9.1 & 8.4 & 8.8 & 10.2 \\
\hline Median annual household income in zip code, $\$$ & 49,231 & 49,005 & 49,948 & 48,755 \\
\hline Households below federal poverty level, $\%$ & 20.0 & 19.6 & 20.0 & 20.3 \\
\hline Households with children headed by a woman, $\%$ & 12.9 & 12.9 & 12.8 & 13.0 \\
\hline Households receiving public assistance, $\%$ & 4.4 & 3.9 & 4.4 & 4.8 \\
\hline
\end{tabular}

Abbreviations: ACO, accountable care organization; FTE, full-time equivalent; SES, socioeconomic status.

a Source: A web-based survey completed by $\mathrm{CHC}$ medical directors in summer 2017 about the strategies they adopted to support primary and specialty care integration and to improve $\mathrm{CHC}$ /specialist communication with specialists outside $\mathrm{CHCs}$. CHCs were surveyed in the following states: California, Colorado, District of Columbia, Illinois, Louisiana, Maine, Minnesota, New Jersey, Oregon, Utah, Vermont, Washington, and Wisconsin.

${ }^{\mathrm{b}}$ Using a 1-factor confirmatory factor analysis, we constructed a composite measure of $\mathrm{CHC} / \mathrm{specialist}$ integration to summarize the breadth of strategies used by $\mathrm{CHCs}$ to achieve greater integration with specialty care providers. We categorized $\mathrm{CHCs}$ as having low, medium, and high levels of integration by dividing $\mathrm{CHCs}$ into tertiles based on the composite.

${ }^{\mathrm{c}}$ The composite measure of SES has a mean of 0 and standard deviaion of 1 . A value $<0$ denotes a service area with an SES level below the mean.

The opinions expressed by authors contributing to this journal do not necessarily reflect the opinions of the U.S. Department of Health and Human Services, the Public Health Service, the Centers for Disease Control and Prevention, or the authors' affiliated institutions. 
Table 2. Strategies Used by Community Health Centers $(\mathrm{CHCs})(\mathrm{N}=215)$ to Support the Integration of CHCs and Specialty Care Providers, $2017^{\mathrm{a}}$

\begin{tabular}{|c|c|c|c|c|}
\hline \multirow[b]{2}{*}{ Strategy } & \multirow[b]{2}{*}{ All CHCs, \% } & \multicolumn{3}{|c|}{ By Tertile of Integration, $\%^{b}$} \\
\hline & & Lowest & Middle & Highest \\
\hline \multicolumn{5}{|l|}{ Improving referrals } \\
\hline $\begin{array}{l}\text { Establish agreements with specialists about the types of referrals specialists will accept or } \\
\text { information the health center will provide when making a referral }\end{array}$ & 70.2 & 42.3 & 74.7 & 93.2 \\
\hline Make appointments with specialists on behalf of $\mathrm{CHC}$ patients & 58.6 & 47.9 & 60.6 & 67.1 \\
\hline Participate in electronic consults (e-consults) with specialists & 43.7 & 29.6 & 42.3 & 58.9 \\
\hline Remind CHC patients of upcoming appointments with specialists & 36.3 & 19.7 & 32.4 & 56.2 \\
\hline \multicolumn{5}{|l|}{ Aligning goals with specialists } \\
\hline Participate in quality improvement projects or health promotion initiatives with specialists ${ }^{c}$ & 71.2 & 18.3 & 95.4 & 99.2 \\
\hline \multicolumn{5}{|l|}{ Exchanging information } \\
\hline No electronic exchange of patient information & 49.8 & 66.2 & 46.5 & 37.0 \\
\hline Send data electronically to specialist (without real-time EHR access) & 25.6 & 18.3 & 33.8 & 24.7 \\
\hline Read specialists' EHRs in real time & 24.7 & 15.5 & 19.7 & 38.4 \\
\hline \multicolumn{5}{|l|}{ Improving access } \\
\hline Specialists on-site at the health center provided any care during the past 6 months & 80.5 & 70.4 & 83.1 & 87.7 \\
\hline $\begin{array}{l}\text { Few affiliations with local hospitals or health systems among } \mathrm{CHC} \text { physicians impact } \mathrm{CHC} \text { 's } \\
\text { ability to obtain timely specialty care for patients }\end{array}$ & 41.3 & 26.2 & 25.7 & 18.3 \\
\hline Participate in telemedicine (excluding e-consults) with specialists & 29.3 & 28.2 & 19.7 & 39.7 \\
\hline
\end{tabular}

Abbreviations: EHR, electronic health record.

a Source: A web-based survey completed by $\mathrm{CHC}$ medical directors during summer 2017 about the strategies they adopted to support primary and specialty care integration and to improve $\mathrm{CHC}$ /specialist communication with specialists outside $\mathrm{CHCs}$. CHCs were surveyed in the following states: California, Colorado, District of Columbia, Illinois, Louisiana, Maine, Minnesota, New Jersey, Oregon, Utah, Vermont, Washington, and Wisconsin.

${ }^{\mathrm{b}}$ Using a 1-factor confirmatory factor analysis, we constructed a composite measure of $\mathrm{CHC} / \mathrm{specialist}$ integration to summarize the breadth of strategies used by $\mathrm{CHCs}$ to achieve greater integration with specialty care providers. We categorized $\mathrm{CHCs}$ as having low, medium, and high levels of integration by dividing $\mathrm{CHCs}$ into tertiles based on the composite.

${ }^{\mathrm{C}}$ Participation in quality improvement initiatives and participation in health promotion initiatives with specialists were combined into a single variable because the 2 items were highly correlated. 
Table 3. Association Between Integration of Community Health Centers (CHCs) and Specialty Care Providers and Screening for Colorectal and Cervical Cancers, $2017^{\mathrm{a}}$

\begin{tabular}{|c|c|c|}
\hline \multirow[b]{2}{*}{ Factor } & \multicolumn{2}{|c|}{ Coefficient (SE) $[P$ Value $]$} \\
\hline & $\begin{array}{c}\text { Association With Rate of Colorectal Cancer } \\
\text { Screening }\end{array}$ & $\begin{array}{c}\text { Association With Rate of Cervical Cancer } \\
\text { Screening }\end{array}$ \\
\hline \multicolumn{3}{|l|}{ Tertile of integration $^{b}$} \\
\hline Lowest & Reference & Reference \\
\hline Middle & $5.35(2.62)[.04]$ & $6.99(2.60)[.008]$ \\
\hline Highest & 5.59 (2.79) [.047] & $6.83(2.69)[.01]$ \\
\hline \multicolumn{3}{|l|}{$\mathrm{CHC}$ characteristics } \\
\hline Number of service sites & $0.04(0.11)[.70]$ & $0.18(0.10)[.06]$ \\
\hline Racial/ethnic minority patients, \% & $0.09(0.08)[.24]$ & $0.23(0.07)[.001]$ \\
\hline Uninsured patients, \% & $-0.35(0.12)[.005]$ & $-0.21(0.12)[.09]$ \\
\hline Medicaid patients, $\%$ & $-0.33(0.10)[.002]$ & $-0.11(0.10)[.30]$ \\
\hline Primary care FTE per 10,000 patients & $0.19(0.19)[.31]$ & $0.49(0.21)[.02]$ \\
\hline Enabling-service FTE per 10,000 patients & $-0.12(0.08)[.12]$ & $-0.12(0.09)[.21]$ \\
\hline $\mathrm{CHC}$ has a chaotic environment & $-2.99(3.04)[.33]$ & $-1.63(2.78)[.56]$ \\
\hline Physician turnover affects quality & $3.19(2.30)[.17]$ & $-1.53(2.18)[.48]$ \\
\hline \multicolumn{3}{|l|}{ Regional characteristics } \\
\hline Rural & $-1.68(3.53)[.63]$ & $-2.29(3.58)[.52]$ \\
\hline Socioeconomic status of $\mathrm{CHC}$ service area & $-0.37(1.58)[.82]$ & $-2.75(1.42)[.05]$ \\
\hline State-expanded Medicaid & $-0.67(4.27)[.88]$ & $-6.89(4.16)[.10]$ \\
\hline State has Medicaid ACO & $-0.63(2.52)[.80]$ & $2.16(2.46)[.38]$ \\
\hline Intercept & $58.4(8.5)[<.001]$ & $48.3(8.4)[<.001]$ \\
\hline
\end{tabular}

Abbreviations: ACO, accountable care organization; FTE, full-time equivalent.

a Source: A web-based survey completed by $\mathrm{CHC}$ medical directors $(\mathrm{N}=215)$ during summer 2017 about the strategies they adopted to support primary and specialty care integration and to improve $\mathrm{CHC} /$ specialist communication with specialists outside $\mathrm{CHCs}$. CHCs were surveyed in the following states: California, Colorado, District of Columbia, Illinois, Louisiana, Maine, Minnesota, New Jersey, Oregon, Utah, Vermont, Washington, and Wisconsin.

${ }^{b}$ Using a 1-factor confirmatory factor analysis, we constructed a composite measure of $\mathrm{CHC} /$ specialist integration to summarize the breadth of strategies used by $\mathrm{CHCs}$ to achieve greater integration with specialty care providers. We categorized $\mathrm{CHCs}$ as having low, medium, and high levels of integration by dividing $\mathrm{CHCs}$ into tertiles based on the composite.

The opinions expressed by authors contributing to this journal do not necessarily reflect the opinions of the U.S. Department of Health and Human Services, the Public Health Service, the Centers for Disease Control and Prevention, or the authors' affiliated institutions. 


\section{Appendix. Survey Items Used to Examine Integration of Community Health Centers With Specialists}

\begin{tabular}{|c|c|c|c|}
\hline Survey items & Response Options & Variable Construction & $\begin{array}{l}\text { Included in Integration } \\
\text { Measure }\end{array}$ \\
\hline \multicolumn{4}{|l|}{$\mathrm{CHC} /$ specialist communication } \\
\hline $\begin{array}{l}\text { 1, In the past } 6 \text { months, for your health center's patients who needed services } \\
\text { from specialists outside of your health center, how frequently did clinicians or staff } \\
\text { in your health center... }\end{array}$ & \multirow[t]{5}{*}{$\begin{array}{l}\text { Never, rarely, } \\
\text { sometimes, often, } \\
\text { always }\end{array}$} & \multirow[t]{5}{*}{$\begin{array}{l}\text { Dichotomous variable } \\
\text { (often/always vs } \\
\text { never/rarely/sometimes) }\end{array}$} & \\
\hline A) Know that a visit to a specialist happened & & & \\
\hline B) Know the outcome of the visit & & & \\
\hline $\begin{array}{l}\text { C) Receive clear follow-up or care management recommendations when needed } \\
\text { following the specialist visit }\end{array}$ & & & \\
\hline D) Receive results or recommendations from the specialist in a timely manner & & & \\
\hline \multicolumn{4}{|l|}{ CHCs' integration with specialists } \\
\hline $\begin{array}{l}\text { 2. Please indicate the number of patients for whom your health center sought to } \\
\text { obtain specialty care over the past } 6 \text { months }\end{array}$ & \multirow{3}{*}{$\begin{array}{l}\text { No patients, a few } \\
\text { patients, some } \\
\text { patients, most } \\
\text { patients, all patients }\end{array}$} & \multirow{3}{*}{$\begin{array}{l}\text { Dichotomous variable (no } \\
\text { patients vs a few } \\
\text { patients/some } \\
\text { patients/most patients/all } \\
\text { patients) }\end{array}$} & \\
\hline $\begin{array}{l}\text { A) Specialists outside of your health center through electronic consults (e- } \\
\text { consults)? }\end{array}$ & & & $\mathrm{x}$ \\
\hline $\begin{array}{l}\text { B) Specialists outside of your health center through telemedicine applications } \\
\text { other than e-consults? }\end{array}$ & & & $\mathrm{x}$ \\
\hline $\begin{array}{l}\text { 3. During the past } 2 \text { years, how often has your health center participated in quality } \\
\text { improvement projects with specialists outside of your health center? }\end{array}$ & $\begin{array}{l}\text { Never, rarely, } \\
\text { sometimes, often, } \\
\text { always }\end{array}$ & $\begin{array}{l}\text { Dichotomous variable } \\
\text { (often/always vs } \\
\text { never/rarely/sometimes) }\end{array}$ & $x$ \\
\hline $\begin{array}{l}\text { 4. During the past } 2 \text { years, how often has your health center participated in health } \\
\text { promotion initiatives (eg, hypertension awareness) with specialists outside of your } \\
\text { health center? }\end{array}$ & $\begin{array}{l}\text { Never, rarely, } \\
\text { sometimes, often, } \\
\text { always }\end{array}$ & $\begin{array}{l}\text { Dichotomous variable } \\
\text { (often/always vs } \\
\text { never/rarely/sometimes) }\end{array}$ & $x$ \\
\hline $\begin{array}{l}\text { 5. Over the past } 6 \text { months, please indicate the number of patients for whom your } \\
\text { health center sought to obtain specialty care via specialists on-site at your health } \\
\text { center? }\end{array}$ & $\begin{array}{l}\text { No patients, a few } \\
\text { patients, some } \\
\text { patients, most } \\
\text { patients, all patients }\end{array}$ & $\begin{array}{l}\text { Dichotomous variable (no } \\
\text { patients vs a few } \\
\text { patients/some } \\
\text { patients/most patients/all } \\
\text { patients) }\end{array}$ & $\mathrm{X}$ \\
\hline $\begin{array}{l}\text { 6. In the past } 6 \text { months, for your health center's patients who needed services } \\
\text { from specialists outside of your health center... }\end{array}$ & \multirow{3}{*}{$\begin{array}{l}\text { Never, rarely, } \\
\text { sometimes, often, } \\
\text { always }\end{array}$} & \multirow{3}{*}{$\begin{array}{l}\text { Dichotomous variable } \\
\text { (often/always vs } \\
\text { never/rarely/sometimes) }\end{array}$} & \\
\hline $\begin{array}{l}\text { A) How frequently did clinicians or staff in your health center make appointments } \\
\text { with specialists on behalf of your health center's patients? }\end{array}$ & & & $\mathrm{x}$ \\
\hline $\begin{array}{l}\text { B) How frequently did clinicians or staff in your health center remind your health } \\
\text { center's patients of upcoming appointments with these specialists? }\end{array}$ & & & $\mathrm{x}$ \\
\hline $\begin{array}{l}\text { 7. Please indicate how often the following factors impact your health center's } \\
\text { ability to obtain timely specialty care for its patients: Few affiliations with local } \\
\text { hospitals or health systems among your health center's physicians? }\end{array}$ & $\begin{array}{l}\text { Never, rarely, } \\
\text { sometimes, often, } \\
\text { always, not applicable }\end{array}$ & $\begin{array}{l}\text { Dichotomous variable } \\
\text { (never/rarely vs } \\
\text { often/always/sometimes) }\end{array}$ & $\mathrm{X}$ \\
\hline $\begin{array}{l}\text { 8A. Does your health center have written or verbal agreements with specialists } \\
\text { about either the types of referrals specialists will accept or information your health } \\
\text { center will provide when making a referral? }\end{array}$ & Yes, no & \multirow{3}{*}{$\begin{array}{l}\text { These } 3 \text { items were } \\
\text { combined into a categorical } \\
\text { variable indicating } 1 \text { ) yes to A } \\
\text { or B; 2) no to A and B, but } \\
\text { yes to C, or (3) no to A, B, } \\
\text { and C. }\end{array}$} & \multirow{3}{*}{$\mathrm{x}$} \\
\hline $\begin{array}{l}\text { 8B. Does your health center have written or verbal agreements with specialists } \\
\text { about the type of information specialists will provide to the health center following } \\
\text { the visit? }\end{array}$ & Yes, No & & \\
\hline $\begin{array}{l}\text { 9. Has your health center sought to establish referral agreements with one or } \\
\text { more specialists? }\end{array}$ & Yes, No & & \\
\hline $\begin{array}{l}\text { A) If the } \mathrm{CHC} \text { answered yes to } 8 \mathrm{~A} \text { above, then does the agreement mention the } \\
\text { types of patients to be referred to the specialist (eg, patients with specific } \\
\text { symptoms or conditions)? }\end{array}$ & \multirow[t]{2}{*}{$\begin{array}{l}\text { Never, rarely, } \\
\text { sometimes, often, } \\
\text { always }\end{array}$} & \multirow{2}{*}{$\begin{array}{l}\text { These } 5 \text { items were } \\
\text { combined into a count of the } \\
\text { number of items that were } \\
\text { "always" included in } \\
\text { agreements with specialists }\end{array}$} & \multirow[t]{2}{*}{$\mathrm{x}$} \\
\hline B) If the $\mathrm{CHC}$ answered yes to $8 \mathrm{~A}$ above, then does the agreement mention any & & & \\
\hline
\end{tabular}

${ }^{\text {a }}$ Combined with item below using an "OR" statement. 
(continued)

\begin{tabular}{|c|c|c|c|}
\hline Survey items & Response Options & Variable Construction & $\begin{array}{l}\text { Included in Integration } \\
\text { Measure }\end{array}$ \\
\hline testing to be conducted prior to a referral to the specialist? & & \multirow[t]{4}{*}{ (range, 0-5) } & \\
\hline $\begin{array}{l}\text { C) If the } \mathrm{CHC} \text { answered yes to } 8 \mathrm{~A} \text { above, then does the agreement mention the } \\
\text { information to be provided at the time of a referral to the specialist (eg, test } \\
\text { results, patient's medical record or clinical notes)? }\end{array}$ & & & \\
\hline $\begin{array}{l}\text { D) If the } \mathrm{CHC} \text { answered yes to } 8 \mathrm{~B} \text { above, then does the agreement mention that } \\
\text { the specialist send a visit summary to the health center following the specialist } \\
\text { visit? }\end{array}$ & & & \\
\hline $\begin{array}{l}\text { E) If the } \mathrm{CHC} \text { answered yes to } 8 \mathrm{~B} \text { above, then does the agreement mention the } \\
\text { time frame by which specialists should send information to the health center } \\
\text { following the specialist visit? }\end{array}$ & & & \\
\hline \multicolumn{4}{|l|}{ 10. Excluding faxed or scanned documents, how often does your health center ... } \\
\hline A) Send health information electronically to specialists outside your health center? & $\begin{array}{l}\text { Never, rarely, } \\
\text { sometimes, often, } \\
\text { always }\end{array}$ & $\begin{array}{l}\text { Dichotomous variable } \\
\text { (often/always vs } \\
\text { never/rarely/sometimes) }\end{array}$ & $x^{a}$ \\
\hline $\begin{array}{l}\text { B) Receive health information electronically from specialists outside your health } \\
\text { center? }\end{array}$ & $\begin{array}{l}\text { Never, rarely, } \\
\text { sometimes, often, } \\
\text { always }\end{array}$ & $\begin{array}{l}\text { Dichotomous variable } \\
\text { (often/always vs } \\
\text { never/rarely/sometimes) }\end{array}$ & \\
\hline $\begin{array}{l}\text { 11. How often are your staff able to read, in real time, the medical records of the } \\
\text { specialty practices to which you refer your patients? }\end{array}$ & $\begin{array}{l}\text { Never, rarely, } \\
\text { sometimes, often, } \\
\text { always }\end{array}$ & $\begin{array}{l}\text { Dichotomous variable } \\
\text { (often/always vs } \\
\text { never/rarely/sometimes) }\end{array}$ & $\mathrm{X}$ \\
\hline \multicolumn{4}{|l|}{ Characteristics of CHCs } \\
\hline $\begin{array}{l}\text { 12. Please indicate how often the following factors impact your health center's } \\
\text { ability to care for its patients. }\end{array}$ & \multirow{3}{*}{$\begin{array}{l}\text { Never, rarely, } \\
\text { sometimes, often, } \\
\text { always, not applicable }\end{array}$} & \multirow{3}{*}{$\begin{array}{l}\text { Dichotomous variable } \\
\text { (often/always vs } \\
\text { never/rarely/sometimes) }\end{array}$} & \\
\hline A) Chaotic environment within your health center & & & \\
\hline B) Physician turnover & & & \\
\hline
\end{tabular}

${ }^{\text {a }}$ Combined with item below using an "OR" statement. 